\title{
Having a Co-Twin With Attention-Deficit Hyperactivity Disorder
}

\author{
Megan R. McDougall, David A. Hay, and Kellie S. Bennett \\ School of Psychology, Curtin University of Technology, Perth, Western Australia, Australia
}

\begin{abstract}
A ttention-deficit hyperactivity disorder (ADHD) is a common childhood disorder which occurs more often in twins than singletons. This article focuses on the psychosocial consequences of having a co-twin with ADHD. Specifically, the level of anxiety (generalized and separation) in non-ADHD children who have a co-twin with ADHD is examined using data from the Australian Twin ADHD Project (ATAP). Parental report data on 501 dizygotic (DZ) twin pairs aged 6 to 15 and their siblings were used to examine (i) anxiety symptoms in twin pairs discordant for ADHD, (ii) how the effects of an ADHD twin on their co-twin and siblings are related to the type of ADHD, and (iii) whether the effects are greater for the nonaffected twin than nontwin siblings. Results show that anxiety was high in co-twins of children with the combined subtype of ADHD, with increased symptoms of both generalized and separation anxiety. Inattentive ADHD had smaller effects, which were confined to generalized anxiety and were specific to the co-twin rather than other siblings. These results have clinical implications in managing the entire multiple birth family where one twin has ADHD, and also has implications for genetic analysis in modeling the relationship of $A D H D$ to internalizing disorders.
\end{abstract}

Attention-deficit hyperactivity disorder (ADHD) has been described as one of the most prevalent childhood disorders in the world (Slomkowski et al., 1995), affecting an estimated $6 \%$ of children and adolescents within the Australian population (Graetz et al., 2001). As ADHD accounts for such a large proportion of mental illness in children, there has been a growing interest in the nature and impact this disorder has on the individual with ADHD, the family environment, and individual family members.

There is some evidence that ADHD may be slightly more common in twins (Hay, 2005). Additionally, using the unitary Diagnostic and Statistical Manual of Mental Disorders (3rd ed., rev.; DSM-III-R; American Psychiatric Association, 1987) definition of ADHD, Levy et al. (1996) found a higher rate of ADHD was associated with the speech and language problems common in twins (Mogford-Bevan, 1999). One twin phenomenon found in some, but not all, measures of ADHD is that correlations of dizygotic (DZ) twins are substantially less than half that found for monozygotic
(MZ) twins (Rietveld et al., 2003). As this appears specific to parental ratings of ADHD, it is unlikely to be due to either sibling interaction or to genetic dominance but can be explained by parental bias, where parents exaggerate the differences between their twins in ADHD symptomatology. Beyond this, little is known about the DZ co-twin who does not have ADHD, despite the prevalence of the disorder and the stigma often associated with it. What is it like living at home and at school with your twin brother (or, less often, sister) who has difficulties associated with ADHD?

Given this lack of knowledge about the impact of ADHD on twins and their families, we start with a summary of how ADHD affects a child, the family, the parents, and (nontwin) siblings.

\section{The ADHD Child}

Many studies have highlighted how ADHD impinges on the physical, emotional, and social well-being of a child or adolescent with the disorder. These individuals are at an increased risk of academic underachievement (Barkley, 1997, 1998; Weiss \& Hechtman, 1993; Young, 2000), aggressive behavior (Kitchens et al., 1999), and substance use (Wilens et al., 1997).

Of particular concern is the negative impact the disorder may have on the child or adolescent's interpersonal relationships. Negative peer relationships often plague many children and adolescents with ADHD. Even after brief periods of contact, individuals with ADHD are often rejected by their peers (Bagwell et al., 2001), and form fewer friendships than those children without the disorder (Bagwell et al., 2001; Landau et al., 1998). There is a tendency for ADHD children to prefer other ADHD children as playmates (Hubbard \& Newcomb, 1991), which raises interesting issues for the bond between twins discordant for ADHD.

\section{Families With an ADHD Child}

Families provide children with important social and communication skills, the ability to set goals and to solve problems, and the underpinnings required to

Received 10 August, 2005; accepted 15 September, 2005.

Address for correspondence: Megan McDougall, School of Psychology, Curtin University of Technology, GPO Box U1987, Perth, WA 6845,

Australia.E-mail: m.mcdougall@curtin.edu.au 
maintain successful relationships (Grenwald-Mayes, 2002). Several studies have identified that families of ADHD children are at an increased risk of negativity and disruption (Barkley, 1997; DuPaul et al., 2001; Smith et al., 2002).

Scahill et al. (1999) examined the psychosocial and clinical correlates of ADHD in a community sample of 449 school children. An increase in the severity of ADHD symptoms was directly associated with higher levels of family dysfunction, even after controlling for the presence of comorbid disorders. Similar findings have been established in clinic-referred samples of children and adolescents with ADHD (Brown \& Pacini, 1989; DuPaul et al., 2001; Smith et al., 2002). For instance, DuPaul et al. (2001) examined the difference in family functioning between 58 preschool children with ADHD and 36 normal control children. In addition to less adaptive coping styles within the family, families of ADHD children were at significant risk of having more problematic relationships and increased levels of family dysfunction, when compared to non-ADHD control children.

\section{Parents of an ADHD Child}

The impact of caring for an ADHD child on the mental health and well-being of parents has been well documented in the literature. The often adverse behaviors demonstrated by children with ADHD have repeatedly been proposed to produce low parenting self-efficacy (Hoza et al., 2000) and low self-esteem in parents (Hoza et al., 2000; Mash \& Johnston, 1983), as well as elevated rates of marital discord (Anastopoulos et al., 1993; Johnston \& Mash, 2001; Murphy \& Barkley, 1996; Shelton et al., 1998) and depression (Anastopoulos et al., 1992; Roizen et al., 1996).

In the last decade, an increasing number of studies have indicated that parents of children diagnosed with ADHD frequently experience elevated amounts of stress within their parenting role (Anastopoulos et al., 1992; Anastopoulos et al., 1993; Baker, 1994; Barkley et al., 1991). An older study by Cunningham and Barkley (1979) reported that the high levels of stress in parents with an ADHD child may be due to the increased caretaking demands required to care for these individuals. In many cases, the behaviors associated with ADHD such as the increased levels of hyperactivity and impulsivity and the difficulty in sustaining attention, are often perceived by the parents as disruptive and annoying, leading to added amounts of stress placed on these primary caregivers.

\section{Siblings of an ADHD Child}

To date, few studies have focused on the long-term psychosocial consequences for the non-ADHD sibling or the discordant twin. The attention directed towards siblings has in several cases been in comparison to the ADHD affected individual, with the focus of the study concentrated around the outcome of the ADHD child. For instance, Tarver-Behring et al. (1985) observed mother-child interactions with ADHD boys and their unaffected siblings. Boys with ADHD demonstrated more conflicting behaviors associated with parental requests than their nonaffected siblings, and had more severe behavior management problems in both free play and structured settings.

Further genetic research has concentrated on the prevalence of developmental disorders in biological brothers or sisters of ADHD children. Specifically, siblings of children with ADHD experience a higher incidence of alcoholism, drug abuse, delinquency, and problematic behaviors, when compared to siblings of children with Down syndrome (Roizen et al., 1996). Additionally, both ADHD and learning disorders have been identified as occurring more frequently in siblings of an ADHD child, when compared to siblings of children with Down syndrome (Roizen et al., 1996), and controls (Biederman et al., 1986, 1992; Faraone et al., 1995).

In a recent qualitative study Kendall (1999) investigated the experiences of siblings with an ADHD brother or sister, and examined how the disorder impinged on their lifestyle and sibling relationship. The study revealed disruption resulting from the negative symptoms and externalizing behaviors of a child with ADHD to be the major complaint of non-ADHD siblings. Non-ADHD siblings reported feelings of anxiousness, worry, and sorrow, due to the absence of a normal family environment, privacy, quiescence, and enjoyable family activities. The same study identified that the disruption felt by siblings of an ADHD child was often overlooked or minimized by parents. Non-ADHD siblings also described not obtaining help from parents when they were experiencing difficulty, and often reported being ignored and distrusted. These siblings tend to react through behaviors such as retaliatory aggression, accommodation, or avoidance.

Although little information exists in regards to the sibling relationship between a child with ADHD and their nonaffected brother/sister, research that is available is largely suggestive of a negative impact on the nonADHD child, as well as an increase in conflicting sibling relationships.

The present study represents the first attempt to examine what happens in pairs of DZ twins where only one has ADHD. The level of anxiety (both generalized and separation) is examined in the non-ADHD co-twin of a child with ADHD. Kendall (1999) emphasized that high anxiety is a significant issue for siblings of children with ADHD. Additionally, it is expected that the anxiety levels in a co-twin of a child with ADHD will be higher than that of a nontwin sibling, as twins are the same age and may often be in the same class, share the same peer group and be more easily compared with each other. Siblings of the twins are also considered to examine the issue of how siblings can be affected by the extra attention and demands of twins in the same family (Hay et al., 1988). Unlike previous studies, the Diagnostic and Statistical Manual of Mental Disorders (4th ed.; DSM- 
IV; American Psychiatric Association, 1994) distinction of three subtypes of ADHD is recognized. Compared with the unitary DSM-III-R, DSM-IV distinguishes those with predominantly inattentive symptoms (ADHD-PI), those with predominantly hyperactive/impulsive symptoms (ADHD-PHI) and the combined type with both (ADHD-C). This distinction may be important for assessing the effects on co-twins and other siblings, as ADHD-C is associated with more comorbid problems such as conduct disorder (Levy et al., 2005) which may impact even more on the family than ADHD.

\section{Method}

\section{Participants}

The Australian Twin ADHD Project (ATAP) has collected extensive data from families of twins registered with the Australian National Health and Medical Research Council Twin Registry. The main data were collected from a cohort of families with twins initially aged 4 to 12 years in 1991, with further data collected in 1994 to 1995 and 1998 to 1999 . A detailed account of the process by which families were selected for inclusion in the ATAP is outlined by Levy et al. (1996) and Hay et al. (2002). The procedure for assessing zygosity is described in Levy et al. (2001). The present study is based on the second wave of the ATAP (1994 to 1995). From the 1885 identified families, 1577 families responded. Of these families, 27 were excluded on the basis of one or more children in the family having a major disability, leaving 1550 eligible families.

MZ pairs were excluded, both because such discordant twins are rare for ADHD, but also because we have (unpublished) data that unlike $\mathrm{DZ}$ twins, their discordance may be associated with birth complications and the confounding factors these may bring to behavioral development. Small sample size necessitated exclusion of DZ twins discordant for the least common ADHD-PHI subtype (24 pairs) and the potentially interesting DZ pairs concordant for ADHD (24 pairs across all three subtypes).

\section{Comparison of Discordant Twins}

Five hundred and one pairs of DZ twins between the ages of 6 and 15 years $(M=10.62, S D=2.58)$ participated in the study and comprised three groups:

1. Discordant for ADHD-PI $(n=63)$. The twin with ADHD had to have five or more inattentive symptoms and four or fewer hyperactive/impulsive symptoms.

2. Discordant for ADHD-C $(n=55)$. The ADHD twin had to have five or more inattentive symptoms and five or more hyperactive/impulsive symptoms.

In both these groups the non-ADHD co-twin had to have no more than two inattentive and two hyperactive/impulsive symptoms.

3. Concordant control group $(n=383)$. Both children had no more than two inattentive and two hyperactive/impulsive symptoms. Given the nonindepen- dence of twins, one was picked at random from each pair in the control group.

There were no significant differences between the ages and genders of twins in each of these three groups.

\section{Comparisons of Singleton Siblings of Discordant Twins}

Twins were matched to a sibling closest in age. As not all twins had a sibling, the sample was reduced to 315 pairs of DZ twins between the ages of 6 and 15 years $(M=10.50, S D=2.49)$. The age of siblings ranged from 3 to $21(M=11.67, S D=3.44)$. Ages and genders of twins and siblings from each group were not significantly different.

\section{Measures}

Items measuring ADHD were based on DSM-IV criteria and were assessed by maternal report. Nine items related to inattentive symptoms and a further nine to hyperactive/impulsive symptoms. A full description and listing of these items can be found in Levy et al. (2001). A 4-point scale was used to rate ADHD symptoms, which were coded as 1 (not at all), 2 (just a little/sometimes), 3 (pretty much/often), and 4 (very much/very often). The internal reliability of the scales indicated high coefficient alphas for the inattentive symptoms (.920) and for the hyperactive/impulsive symptoms (.897; Levy et al., 2005).

Generalized anxiety (GA) and separation anxiety (SA) were similarly assessed by maternal report on items derived from DSM-IV criteria. Nine items measured GA and eight items measured SA. Symptoms of both types of anxiety were coded in the same manner as ADHD symptoms. The internal reliability of these scales also showed high coefficient alphas for SA symptoms (.743) and GA symptoms (.911; Levy et al., 2005).

The items measuring the symptoms of ADHD, SA, and GA do not produce a formal diagnosis, as impairment criteria were not included (Levy et al., 2005). This is not an issue for SA and GA which are being assessed as continuous dependent variables. ADHD is dichotomized and the choice of five rather than the six symptoms plus impairment needed for DSM-IV criteria was based on prior experience with these parent report instruments, and the fact parents typically report more symptoms during a standard diagnostic interview (Levy et al., 1997).

\section{Results}

The mean number of symptoms of SA and GA for twin pairs who are 1) discordant for inattentive ADHD, 2) discordant for combined ADHD and 3) have no ADHD symptoms are presented in Table 1.

There are three potential comparisons, some of which are directional and so one-tailed $t$ tests have been used:

Do twins with ADHD have higher anxiety than their non-ADHD co-twin? Children with combined ADHD have significantly higher SA than their non-ADHD cotwin (Table 1). Children who have either type of ADHD (inattentive or combined) have significantly 
Table 1

Mean Scores on Separation and Generalized Anxiety Measures in Twin Pairs Discordant for ADHD and Concordant Twins Without ADHD

\begin{tabular}{|c|c|c|c|c|c|c|c|}
\hline & \multicolumn{3}{|c|}{$\begin{array}{l}\text { Discordant inattentive } \\
\qquad(N=63)\end{array}$} & \multicolumn{3}{|c|}{$\begin{array}{l}\text { Discordant combined } \\
\qquad(N=55)\end{array}$} & \multirow{2}{*}{$\begin{array}{l}\text { Concordant control } \\
(N=383) \\
\text { No ADHD }\end{array}$} \\
\hline & ADHD & No ADHD & Significance & ADHD & No ADHD & Significance & \\
\hline Separation anxiety & 0.90 & 0.75 & & 2.80 & 1.62 & $.017^{*}$ & 0.66 \\
\hline Generalized anxiety & 2.87 & 1.60 & $.008^{* *}$ & 5.18 & 2.62 & $.002^{* *}$ & 0.90 \\
\hline
\end{tabular}

Note: * significant at the .05 level; ${ }^{* *}$ significant at the .01 level.

higher levels of GA than their non-ADHD co-twin. This suggests that symptoms of hyperactivity/impulsivity (present only in the combined ADHD group) may be important in the relationship between SA and ADHD.

Does the level of anxiety differ between ADHD subtypes? Children with combined ADHD had significantly higher levels of both SA, $t(69.76)=2.635$, $p=.010$, and GA, $t(91.49)=2.270, p=.026$, than chil dren with inattentive ADHD.

What about the anxiety levels in the non-ADHD cotwin? The co-twins of children with combined ADHD had significantly higher levels of SA, $t(57.71)=1.981$, $p=.026$, and GA, $t(76.17)=2.055, p=.021$, than cotwins of non-ADHD children. Additionally, the co-twins of children with combined ADHD had higher levels of SA, $t(72.22)=1.691, p=.047$, than the cotwins of children with inattentive ADHD. While symptoms of hyperactivity/impulsivity may contribute to higher anxiety, this needs to be interpreted with caution as the difference was not significant after Bonferroni correction.

\section{Comparison of Siblings of Twins Discordant for ADHD}

Table 2 outlines the mean number of anxiety symptoms in nontwin siblings who have one $\mathrm{DZ}$ twin brother or sister with inattentive or combined ADHD. The mean number of anxiety symptoms for the control group is also given in Table 2. As not all twin families have siblings, the number of co-twins are smaller than in Table 1 but the means are very similar. No differences were found within each of the three groups between the SA levels of co-twins and siblings. However, siblings of children with combined ADHD had significantly higher SA scores, $t(31.04)=1.857, p=.036$, than in the control group (who had no ADHD siblings). The finding of higher SA was also identified in the co-twins of children with combined ADHD (Table 1).

Results for GA showed quite a different picture. Co-twins of those with inattentive ADHD had higher levels of GA than did their nontwin siblings, $t(37)=2.514, p=.016$, who were no different from siblings of the control twins. Siblings in the combined group showed the highest levels of all and much higher than siblings of either the inattentive or the control twins, $t(34.80)=2.505$ and $t(31.23)=2.457$, respectively, both $p<.01$.

\section{$\overline{\text { Discussion }}$}

While there have been many twin studies of ADHD, these have focused almost exclusively on the extent of the MZ and DZ twin similarity. To our knowledge this is the first study that has focussed on the psychosocial impact of what it is like to have a co-twin who has ADHD, and all of the implications that this has for family functioning. Indeed, studies of discordant twins from this aspect are rare across all conditions. As we recently discussed (Hay, 2005), the only study of the psychological effects on the co-twin of one of the disorders most commonly elevated in twins, namely cerebral palsy, was done 50 years ago (Shere, 1956). There has been limited research into this area despite the fact that the effects on the cotwin of a child with ADHD are likely to be substantial and greater than in conditions such as cerebral palsy. In contrast to the family with a child who has cerebral palsy, which is more likely to attract sympathy, the experience of a family with a child with ADHD is likely to be negative because ADHD is still strongly stigmatized.

Table 2

Mean Scores on Separation and Generalized Anxiety Measures in Co-Twins and Siblings of Children With ADHD and Concordant Non-ADHD Children

\begin{tabular}{|c|c|c|c|c|c|c|}
\hline & \multicolumn{2}{|c|}{$\begin{array}{l}\text { Discordant inattentive } \\
\qquad(N=38)\end{array}$} & \multicolumn{2}{|c|}{$\begin{array}{l}\text { Discordant combined } \\
\qquad(N=31)\end{array}$} & \multicolumn{2}{|c|}{$\begin{array}{c}\text { Concordant control } \\
\qquad(N=246)\end{array}$} \\
\hline & Twin & Sibling & Twin & Sibling & Twin & Sibling \\
\hline Separation anxiety & 0.68 & 0.63 & 1.55 & 1.74 & 0.56 & 0.53 \\
\hline Generalized anxiety & 1.71 & 0.79 & 2.35 & 3.32 & 0.73 & 0.91 \\
\hline
\end{tabular}


In this study we have chosen to focus on two of the more common anxiety disorders, given the Kendall (1999) study which found this to be a real problem for siblings. In the current study it is unclear just why anxiety is more common in co-twins and siblings of a DZ ADHD child. Given the criteria for a discordant pair meant that the co-twin had to have two or fewer ADHD symptoms, it is unlikely that the anxiety can be explained as a common comorbid condition with $\mathrm{ADHD}$, nor through the limited evidence for a genetic overlap of ADHD and anxiety conditions (Pliszka et al., 1999). The same authors discuss the overlap of symptoms, but the overlap of GA symptoms is mainly with those of inattentive ADHD where the effect on co-twins and siblings is much less than in the combined subtype. The most likely reason is the embarrassment and unpredictability of having a brother or sister with ADHD in your school or, as is common with twins, in your own classroom. While the effects are greatest for the combined type and their more obvious impulsive behavior, children with the inattentive type often fail to respond to social cues which may be just as distressing for the cotwin or sibling.

\section{Clinical Implications}

Recently we have used the ABCX model of family stressors to identify effects specific to a multiple birth (Hay, 2005; Hay \& Steed, 2005). While not examining the stressors of an ADHD twin on the parents, in the present study there are clearly effects on the cotwin and on the siblings that need to be considered in treating the family, rather than just the child with ADHD. In a study of singleton families with an ADHD child, McDougall (2002) found children were acutely aware of the effect of stimulant medication on their ADHD sibling. Such effects could only be greater in the twin situation and may be an additional factor in deciding whether such medication is appropriate. Even if the behavior of the ADHD child is improved, there may still be ongoing anxiety in the co-twins and siblings that needs to be addressed.

Data on stimulant medication were also collected during this study to examine the potential treatment effects for the ADHD child and possibly their discordant twin. This wave of the study was done in 1994-1995 when the use of stimulant medication for ADHD was considerably lower (Berbatis et al., 2002). As a result, only one child with inattentive type ADHD was taking stimulant medication and 11 children with the combined type. It should also be considered that there are many extraneous factors beyond the severity of the ADHD such as the attitudes of the parents and clinicians, which may contribute to whether the specific child receives stimulant medication (Sawyer et al., 2004). While the study by McDougall (2002) is largely suggestive of stimulant medication having a favorable effect on the sibling relationship and on the family environment as a whole, very little is known on this topic. It is anticipated that new data currently being collected by the ATAP may provide important information on the effects of stimulant medication for the ADHD child, as well as its impact on co-twins and the family.

\section{Limitations}

Even with such a large population sample of DZ twins, the number of discordant twin pairs for the three ADHD subtypes was necessarily small. Indeed the number with the least frequent ADHD subtype, the hyperactive/impulsive subtype, was too small to be informative. Yet this group could prove to be the most important in determining if the consistently greater effects of having a combined-type co-twin are associated specifically with the hyperactive/impulsive symptoms and/or with the range of comorbid conditions especially common in this subtype (Levy et al., 2005). The data has come only from parental report which has limitations, especially where the parent may be depressed (Briggs-Gowan et al., 1996), as happens both in multiple birth families in general (Hay \& Steed, 2005) and in nontwin ADHD families, as reviewed earlier. Many of the children were too young to provide reliable self-report data, but a study is currently underway of a new ATAP cohort with families where the twins are 12 years and above.

\section{Conclusion}

This study has raised an issue that could be addressed with other extensive databases on child twins. For example, the Dutch studies that have examined issues around rater bias in the assessment of ADHD (Rietveld et al., 2003) use questionnaires such as the Child Behavior Checklist which have extensive information on internalizing disorders. The idea that an externalizing behavioral problem such as ADHD may impact upon internalizing symptoms in the co-twin goes beyond conventional modeling of comorbidity to the area of modeling causality across disorders, which has rarely been considered. At the same time, it raises additional practical issues around the separation of twins in school (Tully et al., 2004) - is it detrimental for a nonaffected co-twin to be in the same class as a twin brother or sister with ADHD?

\section{Acknowledgments}

We thank the Australian National Health and Medical Research Council who funded this work and the many families recruited through the Australian Multiple Birth Foundation and the Australian Twin Registry, who gave their time to complete our questionnaires.

\section{References}

American Psychiatric Association. (1987). Diagnostic and statistical manual of mental disorders (3rd ed., rev.). Washington, DC: Author.

American Psychiatric Association. (1994). Diagnostic and statistical manual of mental disorders (4th ed.). Washington, DC: Author. 
Anastopoulos, A. D., Guevremont, D. C., Shelton, T. L., \& DuPaul, G. J. (1992). Parenting stress among families of children with attention deficit hyperactivity disorder. Journal of Abnormal Child Psychology, 20, 503-520.

Anastopoulos, A. D., Shelton, T. L., DuPaul, G. J., \& Guevremont, D. C. (1993). Parent training for attention-deficit hyperactivity disorder: Its impact on parent functioning. Journal of Abnormal Child Psychology, 21, 581-596.

Bagwell, C. L., Molina, B. S., Pelham, W. E., \& Hoza, B. (2001). Attention-deficit hyperactivity disorder and problems in peer relations: Predictions from childhood to adolescence. Journal of the American Academy of Child and Adolescent Psychiatry, 40, 1285-1292.

Baker, D. B. (1994). Parenting stress and ADHD: A comparison of mothers and fathers. Journal of Emotional and Behavioral Disorders, 2, 46-50.

Barkley, R. A. (1997). ADHD and the nature of selfcontrol. New York: The Guilford Press.

Barkley, R. A. (1998). Attention-deficit byperactivity disorder: A handbook for diagnosis and treatment (2nd ed.). New York: The Guilford Press.

Barkley, R. A., Fischer, M., Edelbrock, C., \& Smallish, L. (1991). The adolescent outcome of hyperactive children diagnosed by research criteria. III: Mother-child interactions, family conflicts and maternal psychopathology. Journal of Child Psychology and Psychiatry, 32, 233-255.

Berbatis, C. G., Sunderland, V. B., \& Bulsara, M. (2002). Licit psychostimulant use in Australia, 1984-2000: International and jurisdictional comparison. Medical Journal of Australia, 177, 539-543.

Biederman, J., Faraone, S. V., Keenan, K., Benjamin, J., Krifcher, B., Moore, C., Sprich-Buckminster, S., Ugaglia, K., Jellinek, M. S., Steingard, R., Spencer, T., Norman, D., Kolodny, R., Kraus, I., Perrin, J., Keller, M.B., \& Tsuang, M.T. (1992). Further evidence for family-genetic risk factors in attention deficit hyperactivity disorder: Patterns of comorbidity in probands and relatives in psychiatrically and pediatrically referred samples. Archives of General Psychiatry, 49, 728-738.

Biederman, J., Munir, K., Knee, D., Habelow, W., Armentano, M., Autor, S., Hoge, S. K., \& Waternaux, C. (1986). A family study of patients with attention deficit disorder and normal controls. Journal of Psychiatric Research, 20, 263-274.

Briggs-Gowan, M. J., Carter, A. S., \& Schwab-Stone, M. (1996). Discrepancies among mother, child, and teacher reports: Examining the contributions of maternal depression and anxiety. Journal of Abnormal Child Psychology, 24, 749-765.

Brown, R. T., \& Pacini, J. N. (1989). Perceived family functioning, marital status, and depression in parents of boys with attention deficit disorder. Journal of Learning Disabilities, 22, 581-587.

Cunningham, C. E., \& Barkley, R. A. (1979). The interactions of hyperactive and normal children with their mothers during free play and structured tasks. Child Development, 50, 217-224.

DuPaul, G. J., McGoey, K. E., Eckert, T. L., \& Vanbrakle, J. (2001). Preschool children with attentiondeficit/hyperactivity disorder: Impairments in behavioral, social, and school functioning. Journal of the American Academy of Child and Adolescent Psychiatry, 40, 508-515.

Faraone, S. V., Biederman, J., Chen, W. J., Milberger, S., Warburton, R., \& Tsuang, M. T. (1995). Genetic heterogeneity in attention-deficit hyperactivity disorder (ADHD): Gender, psychiatric comorbidity, and maternal ADHD. Journal of Abnormal Psychology, 104, 334-345.

Graetz, B. W., Sawyer, M. G., Hazell, P. L., Arney, F., \& Baghurst, P. (2001). Validity of DSM-IV ADHD subtypes in a nationally representative sample of Australian children and adolescents. Journal of the American Academy of Child and Adolescent Psychiatry, 40, 1410-1417.

Grenwald-Mayes, G. (2002). Relationship between current quality of life and family of origin dynamics for college students with attention-deficit/hyperactivity disorder. Journal of Attention Disorders, 5, 211-222.

Hay, D. A. (2005). Coping with the special needs child. In I. Blickstein \& L. G. Keith (Eds.), Multiple pregnancy: Epidemiology, gestation and perinatal outcome (pp. 827-835). London: Parthenon Press.

Hay, D. A., MacIndoe, R., \& O’Brien, P. J. (1988). The older sibling of twins. Australian Journal of Early Childhood, 13, 25-28.

Hay, D. A., McStephen, M., Levy, F., \& Pearsall-Jones, J. (2002). Recruitment and attrition in twin register studies of childhood behavior: The example of the Australian twin ADHD project. Twin Research, 5, 324-328.

Hay, D. A., \& Steed, L. (2005). Adaptation and maladaptation in the multiple birth family. In I. Blickstein \& L. G. Keith (Eds.), Multiple pregnancy: Epidemiology, gestation and perinatal outcome (pp. 845-855). London: Parthenon Press.

Hoza, B., Owens, J. S., Pelham, W. E., Swanson, J. M., Conners, C. K., Hinshaw, S. P., Arnold, L. E., \& Kraemer, H. C. (2000). Parent cognitions as predictors of child treatment response in attention deficit/hyperactivity disorder. Journal of Abnormal Child Psychology, 28, 569-583.

Hubbard, J. A., \& Newcomb, A. F. (1991). Initial dyadic peer interaction of attention deficit/hyperactivity disorder and normal boys. Journal of Abnormal Child Psychology, 19, 179-195.

Johnston, C., \& Mash, E. J. (2001). Families of children with attention-deficit/hyperactivity disorder: Review and recommendations for future research. Clinical Child and Family Psychology Review, 4, 183-207. 
Kendall, J. (1999). Sibling accounts of attention deficit hyperactivity disorder (ADHD). Family Process, 38, 117-136.

Kitchens, S. A., Rosen, L. A., \& Braaten, E. B. (1999). Differences in anger, aggression, depression, and anxiety between ADHD and non-ADHD children. Journal of Attention Disorders, 3, 77-83.

Landau, S., Milich, R., \& Diener, M. B. (1998). Peer relations of children with attention deficit hyperactivity disorder. Reading and Writing Quarterly: Overcoming Learning Difficulties, 14, 83-105.

Levy, F., Hay, D. A., Bennett, K. S., \& McStephen, M. (2005). Gender differences in ADHD subtype comorbidity. Journal of the American Academy of Child and Adolescent Psychiatry, 44, 368-376.

Levy, F., Hay, D. A., McLaughlin, M., Wood, C., \& Waldman, I. (1996). Twin-sibling differences in parental reports of ADHD, speech, reading and behaviour problems. Journal of Child Psychology and Psychiatry, 37, 569-578.

Levy, F., Hay, D. A., McStephen, M., Wood, C., \& Waldman, I. (1997). Attention-deficit hyperactivity disorder: A category or a continuum? Genetic analysis of a large-scale twin study. Journal of the American Academy of Child and Adolescent Psychiatry, 36, 737-744.

Levy, F., McStephen, M., \& Hay, D. A. (2001). The diagnostic genetics of ADHD symptoms and subtypes. In F. Levy \& D. Hay (Eds.), Attention, genes, and ADHD (pp. 35-57). Hove, UK: Brunner-Routledge.

Mash, E. J., \& Johnston, C. (1983). Parental perceptions of child behavior problems, parenting self-esteem, and mothers' reported stress in younger and older hyperactive and normal children. Journal of Consulting and Clinical Psychology, 51, 68-99.

McDougall, M. R. (2002). The relationship quality of children with attention deficit hyperactivity disorder and their non-affected siblings. Unpublished honours thesis, Curtin University of Technology, Perth, Australia.

Mogford-Bevan, K. (1999). Twins and their language development. In A. C. Sandbank (Ed.), Twin and triplet psychology: A professional guide to working with multiples (pp. 36-60). Florence, KY: Routledge.

Murphy, K. R., \& Barkley, R. A. (1996). Parents of children with attention deficit/hyperactivity disorders: Psychological and attentional impairment. American Journal of Orthopsychiatry, 66, 93-102.

Pliszka, S. R., Carlson, C. L., \& Swanson, J. M. (1999). ADHD with comorbid disorders: Clinical assessment and management. New York: Guilford Press.

Rietveld, M. J. H., Posthuma, D., Dolan, C. V., \& Boomsma, D. I. (2003). ADHD: Sibling interaction or dominance. An evaluation of statistical power. Behavior Genetics, 33, 247-255.

Roizen, N. J., Blondis, T. A., Irwin, M., Rubinoff, A., Kieffer, J., \& Stein, M. A. (1996). Psychiatric and devel- opmental disorders in families of children with attention-deficit hyperactivity disorder. Archives of Pediatrics and Adolescent Medicine, 150, 203-208.

Sawyer, M. G., Rey, J. M., Arney, F. M., Whatham, J. N., Clark, J. J., \& Baghurst, P. A. (2004). Use of health and school-based services in Australia by young people with attention deficit/hyperactivity disorder. Journal of the American Academy of Child and Adolescent Psychiatry, 43, 1355-1363.

Scahill, L., Schwab-Stone, M., Merikangas, K. R., Leckman, J. F., Zhang, H., \& Kasl, S. (1999). Psychosocial and clinical correlates of ADHD in a community sample of school-age children. Journal of the American Academy of Child and Adolescent Psychiatry, 38, 976-984.

Shelton, T. L., Barkley, R. A., Crosswait, C., Moorehouse, M., Fletcher, K., Barrett, S., Jenkins, L., \& Metevia, L. (1998). Psychiatric and psychological morbidity as a function of adaptive disability in preschool children with aggressive and hyperactive impulsive inattentive behavior. Journal of Abnormal Child Psychology, 26, 475-494.

Shere, M. O. (1956). Socio-emotional factors in families of the twin with cerebral palsy. Exceptional Children, 23, 197-208.

Slomkowski, C., Klein, R. G., \& Mannuzza, S. (1995). Is self-esteem an important outcome in hyperactive children? Journal of Abnormal Child Psychology, 23, 303-315.

Smith, A. J., Brown, R. T., Bunke, V., Blount, R. L., \& Christophersen, E. (2002). Psychosocial adjustment and peer competence of siblings of children with attention deficit/hyperactivity disorder. Journal of Attention Disorders, 5, 165-177.

Tarver-Behring, S., Barkley, R. A., \& Karlsson, J. (1985). The mother-child interactions of hyperactive boys and their normal siblings. American Journal of Orthopsychiatry, 55, 202-209.

Tully, L. A., Mofitt, T. E., Caspi, A., Taylor, A., Kiernan, H., \& Andreou, P. (2004). What effect does classroom separation have on twins' behavior, progress at school, and reading abilities? Twin Research, 7, 115-124.

Weiss, G., \& Hechtman, L. (1993). Hyperactive children grown up: ADHD in children, adolescents, and adults (2nd ed.). New York: The Guilford Press.

Wilens, T. E., Biederman, J., Mick, E., Faraone, S. V., \& Spencer, T. (1997). Attention deficit hyperactivity disor$\operatorname{der}(\mathrm{ADHD})$ is associated with early onset substance use disorders. The Journal of Nervous and Mental Disease, 185, 475-482.

Young, S. (2000). ADHD children grown-up: An empirical review. Counselling Psychology Quarterly, 13, 191-200. 